\title{
Intraamniotic Interleukin-1 Accelerates Surfactant Protein Synthesis in Fetal Rabbits and Improves Lung Stability after Premature Birth
}

\author{
Kristina Bry, ${ }^{\star \ddagger}$ Urpo Lappalainen, ${ }^{\star \ddagger}$ and Mikko Hallman ${ }^{\star \S}$ \\ *Department of Pediatrics, University of California, Irvine, Irvine, California 92697; ${ }^{\ddagger}$ Department of Pediatrics, Vanderbilt University, \\ Nashville, Tennessee 37232; and ${ }^{\S}$ Department of Pediatrics, University of Oulu, Oulu, Finland 90220
}

\begin{abstract}
Intraamniotic infection is associated with increased IL-1 activity in amniotic fluid, increased incidence of preterm labor, and with decreased incidence of respiratory distress syndrome in infants born prematurely. We hypothesized that an elevated IL-1 in amniotic fluid promotes fetal lung maturation. On day 23 or 25 of gestation (term $31 \mathrm{~d}$ ), either IL-1 $\alpha$ (150 or 1,500 ng per fetus) or its antagonist IL-1 receptor antagonist (IL-1ra, $20 \mu \mathrm{g}$ ) was injected to the amniotic fluid sacs in one uterine horn, whereas the contralateral amniotic sacs were injected with vehicle. Within $40 \mathrm{~h}, \mathrm{IL}-1 \alpha$ caused a dose-dependent increase in surfactant protein-A (SP-A) and SP-B mRNAs (maximally, fivefold), without affecting lung growth or increasing inflammatory cells in the lung. Both genders, and upper and lower lung lobes were similarly affected. IL-1ra did not modify SP-A, -B, or -C mRNA. IL-1 increased the intensity of staining of alveolar type II cells for SP-B, and the concentrations of SP-B, -A, and disaturated phosphatidylcholine in bronchoalveolar lavage. The dynamic lung compliance and the postventilatory expansion of lungs were increased two- to fourfold after IL-1 $\alpha$ treatment. In fetal lung explants, IL-1 $\alpha$ increased the expression of SP-A mRNA. IL-1 in amniotic fluid in preterm labor may promote lung maturation and thus be part of a host-defense mechanism that prepares the fetus for extrauterine life. (J. Clin. Invest. 1997. 99:2992-2999.) Key words: pulmonary surfactant - cytokine - respiratory distress syndrome $\bullet$ inflammation $\bullet$ prematurity
\end{abstract}

\section{Introduction}

Pulmonary surfactant is a complex of lipids and proteins synthetized and secreted by the type II alveolar cells into the alveolar epithelial lining where surfactant components act to reduce surface tension at the air-liquid interface. The surfactant lipids, predominantly dipalmitoyl phosphatidylcholine, are critical for generation of low surface tension. Some of the sur-

Data from this work was presented at the International Conference of the American Thoracic Society in Seattle, WA on 7-11 May 1995, and portions of this work have appeared in abstract form (1995. Am. J. Resp. Crit. Care Med. 151:23a).

Address correspondence to Mikko Hallman, M.D., Ph.D., Biocenter Oulu and Department of Pediatrics, Kajaanintie 52 A, FIN90220 Oulu, Finland. Phone: 3588315 5100; FAX: 3588315 5559; E-mail: mhallman@cc.oulu.fi

J. Clin. Invest.

(C) The American Society for Clinical Investigation, Inc. 0021-9738/97/06/2992/08 \$2.00

Volume 99, Number 12, June 1997, 2992-2999 factant proteins that comprise up to $10 \%$ of the total mass of surfactant are also essential for surfactant function. Four surfactant proteins $(\mathrm{SP})^{1}$ have been characterized to date: SP-A, -B, $-\mathrm{C}$, and -D. SP-A is quantitatively the major surfactant apoprotein. The hydrophobic proteins, SP-B and -C, enhance the adsorption, spreading, and stability of the interfacial film $(1,2)$. SP-A binds to surfactant phospholipids and, together with SP-B, enhances the rate of adsorption of dipalmitoyl phosphatidylcholine to the air-liquid interface $(1,3)$. SP-A and -D are mannose binding proteins of the collectin family that are involved in host defense of inflammatory cells (4).

IL-1 denotes two polypeptides, IL- $1 \alpha$ and IL- $1 \beta$, that function as regulators in both local and systemic inflammatory reactions (5). IL- $1 \alpha$ and IL-1 $\beta$ bind to the same cell surface receptors and have similar biological activities. IL-1 participates in host defense mechanisms, particularly in immunologic and hematologic responses, and upregulates the production of vasoactive mediators (PGE, nitric oxide, and others) (6). IL-1 can enhance its own production and that of a wide variety of other cytokines that in multiple ways modulate immune and inflammatory processes (5). Overproduction of IL-1 is likely to be detrimental and leads to debilitation of normal physiological functions (6). However, IL-1 at low concentrations increases natural resistance to infection in animals (7-9). Activated macrophage monocyte is the major source of IL-1; however, B lymphocytes, endothelial, epithelial, mesangial, and smooth muscle cells and fibroblasts also synthesize IL-1 (5). IL-1 has been shown to be produced by decidual cells (10) and the amniochorion (11).

IL-1 receptor antagonist (IL-1ra) is a cytokine that is structurally related to IL- $1 \alpha$ and IL- $1 \beta$, but functions as an IL- 1 inhibitor by competing with IL-1 for occupancy of the IL-1 receptor without inducing signal transduction (12). IL-1ra has been shown to block various IL-1-induced responses on many cells (12). In animal models of various inflammatory diseases, administration of IL-1ra reduces disease severity (5). IL-1ra may be a beneficial treatment for patients with septic shock, although a large clinical trial of IL-1ra treatment in sepsis did not show increased survival in the IL-1ra-treated group (13). Total blockade of IL-1 activity by IL-1ra in infection may in certain instances be harmful $(14,15)$. Monocytes and macrophages, including alveolar macrophages (16), produce and release IL-1ra that is also produced by gestational tissues, such as amnion and decidual cells (17).

Human amniotic fluid during the third trimester contains a high IL-1ra concentration (18). Amniotic fluid IL-1 $\alpha$ and IL-1 $\beta$ concentrations, on the other hand, are usually low in normal gestation, but are elevated in patients with preterm labor oc-

1. Abbreviations used in this paper: BAL, bronchoalveolar lavage; DPC, disaturated phosphatidylcholine; IL-1ra, IL-1 receptor antagonist; SP, surfactant protein. 
curring in the setting of chorioamnionitis as well as in some patients undergoing term labor (19). Infants prenatally exposed to chorioamnionitis are less likely to present with respiratory distress syndrome than newborns not exposed to intraamniotic infection (20). However, respiratory outcome is adversely affected in congenital infections, particularly in group B Streptococcal disease $(20,21)$. At present, it is unknown whether cytokines in amniotic fluid can modulate fetal development. The roles of IL-1 and IL-1ra in fetal lung maturation are likewise unknown. We hypothesized that intraamniotic cytokines influence fetal development and that IL-1 may promote maturation of the surfactant system in the fetal lung.

\section{Methods}

Animals. The animal protocols were approved by the Animal Experimentation Committee of the University of California, Irvine. All procedures conformed to the Animal Welfare Act. Pregnant rabbits were fed ad libitum with laboratory chow.

Animal protocols. The animals were timed-pregnant $( \pm 1 \mathrm{~h}) \mathrm{New}$ Zealand white rabbits. On the indicated days of gestation, the rabbits were anesthetized with an intramuscular injection of ketamine $(50 \mathrm{mg} /$ $\mathrm{kg})$ and xylazine $(5 \mathrm{mg} / \mathrm{kg})$, with local anesthesia using lidocaine. The uterine horns were exposed. A small amount of amniotic fluid was retrieved to ensure the location of the needle tip in the amniotic fluid space before injecting the cytokines as indicated in the following protocols.

Study 1. On day $23.3( \pm 2 \mathrm{~h})$ of gestation, either 150 or $1,500 \mathrm{ng}$ of recombinant human IL-1 $\alpha$ (a kind gift of Dr. Richard Chizzonite, Hoffman-LaRoche, Nutley, NJ) was injected to the amniotic fluid sacs of each fetus in one horn, whereas the sacs in the contralateral horn were injected with the saline vehicle.

Study 2. In another series of animals, likewise on day 23.3 of gestation, the amniotic cavities of fetuses in one horn were injected with $20 \mu \mathrm{g}$ of recombinant human IL-1ra (a kind gift of Dr. Stephen P. Eisenberg, Synergen Inc., Boulder, CO) per fetus, and amniotic fluid sacs in the opposite horn received injections with vehicle.

In both study 1 and 2, the fetuses were killed after $40 \mathrm{~h}$ with intracerebral pentobarbital. The left lungs were removed, and pieces from the upper and lower lobes were immediately chopped to liquid $\mathrm{N}_{2}$ and stored at $-70^{\circ} \mathrm{C}$ before Northern analysis of SP-A, -B, and -C mRNAs. The sex of each animal was determined by identifying testes or ovaries. The right lungs were weighed and assayed for total protein (22), DNA (23), total phospholipid, and disaturated phosphatidylcholine (DPC).

Study 3. A third group of rabbits was injected as in study 1 , but on day 25.3 of gestation. After $40 \mathrm{~h}$, lung function studies were performed on the premature pups of some does. Bronchoalveolar lavage (BAL) was performed on other fetuses, and the lavage return was analyzed for phospholipids, and SP-A and -B. Plasma from these fetuses was analyzed for cortisol. Lungs of yet another group of fetuses were immunostained for SP-B.

Studies on premature rabbits. On day $27.0( \pm 2 \mathrm{~h})$ of pregnancy, the does, operated on day 25.3 of pregnancy, were anesthetized and the uterus was exposed. The fetuses were anesthetized with intraperitoneal ketamine $(1 \mathrm{mg})$ and xylazine $(0.1 \mathrm{mg})$, and sequentially delivered from left and right uterine horn. The team involved in ventilation of animals and subsequent measurements was unaware of the treatment allocation. The trachea of each fetus was cannulated and the pup was manually ventilated for three breaths using $100 \% \mathrm{O}_{2}$. The animals were then placed in a series of plastic, $37^{\circ} \mathrm{C}$ temperaturecontrolled ventilator plethysmographs (24). The rabbits were ventilated for $30 \mathrm{~min}$ with $100 \% \mathrm{O}_{2}$ at a rate of 40 breaths/min, with an inspiratory time of $0.5 \mathrm{~s}$ and a positive end expiratory pressure of $1 \mathrm{~cm}$ $\mathrm{H}_{2} \mathrm{O}$. The peak inspiratory pressures were individually regulated to adjust the tidal volume to $8-10 \mathrm{ml} / \mathrm{kg}$, as measured with a pneumo- tachometer and a differential pressure transducer (DP103; Validyne Engineering Corp., Northridge, CA). The maximum inspiratory pressure used was $40 \mathrm{~cm} \mathrm{H}_{2} \mathrm{O}$. The compliance was calculated by dividing the tidal volume with the difference between the peak inspiratory pressure and the end expiratory pressure. After $30 \mathrm{~min}$ ventilation, the animals were killed with intracerebral pentobarbital, and the endotracheal tube was briefly plugged. Thereafter, the tracheal cannula of each animal was connected to equipment for parallel static pressure-volume recordings. Lungs were inflated through an endotracheal tube in $5 \mathrm{~cm} \mathrm{H}_{2} \mathrm{O}$ pressure increments to $35 \mathrm{~cm} \mathrm{H}_{2} \mathrm{O}$, and then lowered stepwide to $0 \mathrm{~cm} \mathrm{H}_{2} \mathrm{O}$, with $30 \mathrm{~s}$ of stress relaxation at each $5 \mathrm{~cm}$ $\mathrm{H}_{2} \mathrm{O}$ level. After the quasistatic pressure-volume measurement, the chest cage was opened, the diaphragm was inspected for evidence of pneumothoraces, and the lungs were inflated through an endotracheal tube to $30 \mathrm{~cm} \mathrm{H}_{2} \mathrm{O}$ for $30 \mathrm{~s}$. The airway pressure was decreased to $10 \mathrm{~cm} \mathrm{H}_{2} \mathrm{O}$, and the lungs were immersed in $4 \%$ formalin fixative. The aeration of the lungs was viewed on the sagittal sections of the lung, stained with hematoxylin and eosin. The volume density of the alveolar (empty) compartment was determined from the histologic sections by point counting, using total lung parenchyma as reference volume (25).

When indicated, the fetal animals were killed at birth, the chest cage was opened, intracardiac blood was recovered with a heparinized syringe, the trachea was cannulated, and BAL was performed by instilling the airways with $20-30 \mathrm{ml} / \mathrm{kg} 0.9 \% \mathrm{NaCl}$ and thereafter recovering any fluid by gentle suction. This procedure was repeated four times. The total volume of combined BAL return was recorded.

RNA extraction and Northern blot analysis of surfactant proteins. Total RNA from lung tissue was isolated using the single-step acidic guanidium isothiocyanate method (26). RNA was quantitated by determining the absorbance at $260 \mathrm{~nm}$, size separated in a $1.2 \%$ agarose, $5 \%$ formaldehyde gel, transferred to a nylon hybridization membrane (Genescreen; Dupont-NEN, Boston, MA), and cross-linked onto the membrane by ultraviolet light. Membranes were hybridized with random primer ${ }^{32} \mathrm{P}$-labeled probes using a $1.9-\mathrm{kb}$ rabbit SP-A cDNA (a kind gift from Drs. C.R. Mendelson, Univ. Texas, Dallas, TX, and J.M. Snyder, Univ. Iowa Coll. Med., Iowa City, IA), a 1.7-kb rabbit SP-B cDNA (a gift from Dr. F. Possmayer, Univ. Western Ontario, London, Ontario, Canada), and a 0.5-kb rabbit SP-C cDNA (a kind gift from Dr. J.M. Snyder), and autoradiographed. Prehybridization and hybridization were performed in a hybridization incubator (1000; Robbins Scientific Corp., Sunnyvale, CA) at $42^{\circ} \mathrm{C}$; hybridization solutions contained $50 \%$ formamide, $5 \times$ Denhardt's solution, $10 \%$ dextran sulfate, $1 \%$ SDS, and $0.1 \mathrm{mg} / \mathrm{ml}$ salmon sperm DNA in $0.75 \mathrm{M} \mathrm{NaCl}$, $5 \mathrm{mM}$ EDTA, and $50 \mathrm{mM}$ sodium phosphate, $\mathrm{pH}$ 7.4. Posthybridization washes were performed once in $2 \times \mathrm{SSC}, 0.1 \% \mathrm{SDS}$, at ambient temperature for $5 \mathrm{~min}$, twice in $2 \times \mathrm{SSC}, 0.1 \% \mathrm{SDS}$, at $55^{\circ} \mathrm{C}$ for $25 \mathrm{~min}$ each, and final wash three times in $0.2 \times \mathrm{SSC}, 0.1 \% \mathrm{SDS}$, at $55^{\circ} \mathrm{C}$ for 25 min each. To compensate for gel loading artifacts, all membranes were probed with ${ }^{32} \mathrm{P}$-labeled rabbit cytochrome oxidase subunit II (CO II) cDNA (a kind gift from Dr. S. Horowitz, Univ. Rochester, Rochester, NY). The bands were analyzed by video imaging and densitometry using a Macintosh computer and the public domain application National Institutes of Health Image software. Densitometric measurements were normalized to CO II mRNA before making comparisons between lanes in the autoradiograph.

Immunohistochemistry of $S P-B$. The tissues were fixed by immersion in $4 \%$ neutral buffered formaldehyde and embedded in paraffin. 5- $\mu \mathrm{m}$ sections were fixed to glass slides with glue, deparaffinized, and rehydrated. Endogenous peroxidase was blocked with $0.75 \% \mathrm{H}_{2} \mathrm{O}_{2}$ for $40 \mathrm{~min}$ in room temperature and with $0.05 \%$ trypsin in PBS for $20 \mathrm{~min}$ at $37^{\circ} \mathrm{C}$ to unmask antigenic determinants. Nonspecific immunoglobin binding sites were blocked with $5 \%$ horse serum. Sections were then washed and incubated for $2 \mathrm{~h}$ at $37^{\circ} \mathrm{C}$ with the antibody against SP-B (dilution 1:2,000 in PBS containing 0.1\% BSA). Negative controls consisted of nonimmune mouse IgG. Washed sections were then incubated with biotinylated horse anti-mouse antibody (1:400) for $30 \mathrm{~min}$, washed, and incubated for $15 \mathrm{~min}$ with 1:400 
Table I. Body and Lung Weights and Contents of Protein, DNA, Phospholipid, and Disaturated Phosphatidylcholine in the Right

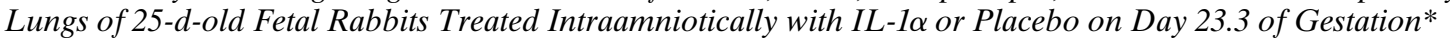

\begin{tabular}{|c|c|c|c|c|c|c|}
\hline & \multicolumn{2}{|c|}{ IL-1 $\alpha(1,500 \mathrm{ng} /$ fetus $)$} & \multicolumn{2}{|c|}{$\mathrm{IL}-1 \alpha(150 \mathrm{ng} / \mathrm{fetus})$} & \multicolumn{2}{|c|}{ IL-1ra (20 $\mu \mathrm{g} / \mathrm{fetus})$} \\
\hline & Drug & Placebo & Drug & Placebo & Drug & Placebo \\
\hline$n$ & 16 & 14 & 17 & 16 & 19 & 18 \\
\hline Fetal body weight (g) & $15.4 \pm 2.2$ & $15.7 \pm 2.1$ & $14.2 \pm 0.7$ & $14.8 \pm 0.4$ & $13.2 \pm 1.2$ & $13.1 \pm 1.1$ \\
\hline \multicolumn{7}{|l|}{ Right lung: } \\
\hline Weight (g) & $0.28 \pm 0.04$ & $0.24 \pm 0.03$ & $0.23 \pm 0.02$ & $0.20 \pm 0.01$ & $0.21 \pm 0.03$ & $0.21 \pm 0.02$ \\
\hline Total protein $(\mathrm{mg})$ & $8.8 \pm 1.5$ & $8.8 \pm 1.1$ & $8.9 \pm 0.7$ & $7.4 \pm 1.1$ & $10.7 \pm 2.4$ & $11.0 \pm 0.9$ \\
\hline DNA (mg) & $1.02 \pm 0.21$ & $0.90 \pm 0.19$ & $1.04 \pm 0.08$ & $0.90 \pm 0.12$ & $1.25 \pm 0.29$ & $1.20 \pm 0.09$ \\
\hline Total phospholipid ( $\mu \mathrm{mol})$ & $2.16 \pm 0.29^{\ddagger}$ & $1.75 \pm 0.34$ & $2.01 \pm 0.25$ & $1.82 \pm 0.41$ & $2.17 \pm 0.27$ & $2.19 \pm 0.27$ \\
\hline $\mathrm{DPC}(\mu \mathrm{mol})$ & $0.33 \pm 0.02^{\ddagger}$ & $0.24 \pm 0.03$ & $0.32 \pm 0.32$ & $0.26 \pm 0.03$ & $0.31 \pm 0.05$ & $0.29 \pm 0.01$ \\
\hline
\end{tabular}

*The amniotic fluids of one uterine horn in each litter were injected with the drug, and the fetuses in the contralateral horn were treated with placebo. Five litters were studied in each treatment group. Values are the means per fetus for each unterine horn \pm SEM. The number of fetuses in each group is indicated. ${ }^{\ddagger} P \leq 0.05$ compared with placebo treatment.

dilution of streptavidin/horseradish peroxidase (1:10). Complexes were visualized by incubation for $10 \mathrm{~min}$ with 3,3-diaminobenzidine in the dark. Sections were washed in distilled water, counterstained in hematoxylin, washed, and dehydrated. The affinity-purified monoclonal anti-porcine SP-B antibody that cross-reacts with rabbit SP-B was used (a kind gift from Dr. Y. Suzuki, Kyoto Univ., Kyoto, Japan).

Detection of SP-A by SDS-PAGE. Detection of SP-A by SDSPAGE was performed essentially as described (27). The lyophilized BAL specimens were extracted three times with butanol. The butanol-insoluble material was size-separated electrophoretically by the method of Laemmli (28) in an SDS-polyacrylamide gel with $12 \%$ acrylamide content under reducing conditions, and electrotransferred to a nitrocellulose membrane. After blocking nonspecific binding sites, the membrane was incubated with a guinea pig anti-rabbit SP-A $(1: 2,000)$, followed by an alkaline phosphatase-conjugated anti-guinea pig antibody, and NBT/BCIP (nitroblue tetrazolium/ 5-bromo-4-chloro-3-indoyl phosphate) color substrate incubation.

Detection of SP-B by immunoassay. SP-B was quantified by the method of Krämer et al. (29). Briefly, samples were mixed 1:1 with propanol in polystyrene microplate. The liquid was removed by evaporation. Trifluoroethanol was added to enhance binding of SP-B to polystyrene, and again the liquid was allowed to evaporate. Phospholipids were removed by washing with a mixture of diisopropylether and butanol, followed by $0.05 \%$ Tween- 20 in PBS. A monoclonal mouse anti-porcine SP-B antibody was bound to the immobilized SP-B, followed by a biotinylated anti-mouse antibody and avidin-labeled peroxidase detection system. The SP-B standard was isolated from rabbit surfactant as described by Beers et al. (30).

Isolation and analysis of lipids. The lipids were extracted by the method of Bligh and Dyer (31), and the samples were concentrated under a stream of $\mathrm{N}_{2}$. The phospholipids were quantitated on the basis of the phosphorus content (27). DPC was isolated using alumina columns after treatment with $\mathrm{OsO}_{4}$ as described (32).

Organ culture. Lung tissue from 22-d-old fetuses was cut into pieces of $\sim 2 \mathrm{~mm}^{3}$ using a sterile razor blade. Five such pieces of lung tissue were placed on a filter paper that was on a metallic grid in a culture dish (Falcon Labware, Becton Dickinson \& Co., Oxnard, CA). The tissue pieces were partly in contact with the atmosphere, partly with the culture medium (33). The medium used was Waymouth's MD 752/1 (Gibco Laboratories, Grand Island, NY) in the presence or absence of IL-1 $\alpha$ (57 or $570 \mathrm{ng} / \mathrm{ml})$ or dibutyryl cAMP (1 mM; Sigma Chemical Co., St. Louis, MO). The culture medium also contained penicillin $(100 \mathrm{U} / \mathrm{ml})$, streptomycin $(100 \mathrm{~g} / \mathrm{ml})$, and fungizone $(0.25$ $\mathrm{g} / \mathrm{ml}$ ). The tissue was maintained in culture at $37^{\circ} \mathrm{C}$ in a humidified atmosphere of $5 \% \mathrm{CO}_{2}$ and $95 \%$ air for $72 \mathrm{~h}$. The culture medium was changed every $24 \mathrm{~h}$. The tissue was harvested, frozen in liquid nitro- gen, and stored at $-70^{\circ} \mathrm{C}$ before analysis of mRNA. In a preliminary study, lung explants, adsorbed to the culture dish, were cyclically exposed to air and the culture medium. Under these conditions, the increase in SP-A mRNA by dibutyryl cAMP was less than during the present culture system (34).

Statistics. All results are shown as means \pm SEM. The significance of the results is evaluated using the $t$ test with Bonferroni correction or using ANOVA.

\section{Drug Placebo}

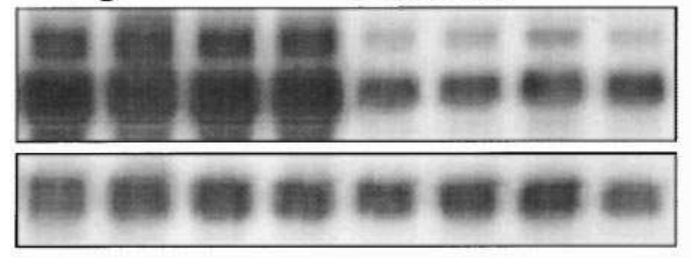

SP-A
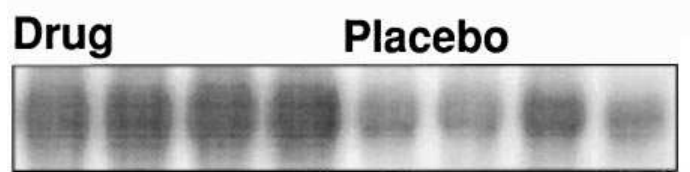

SP-B

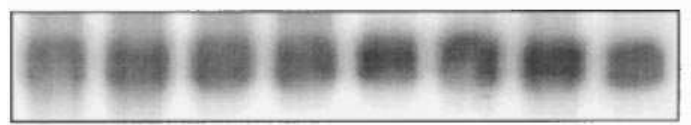

Rco II

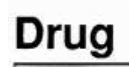

Placebo

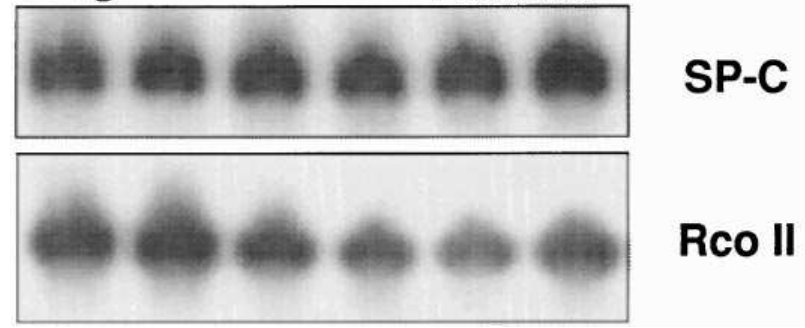

Figure 1. Effect of intraamniotic IL-1 $\alpha$ at 1,500 ng on SP-A, -B, and -C mRNA in two IL- $1 \alpha$-treated and two placebo-treated littermates. Two specimens are shown for each fetus. The one on the left in each pair is from the left lower lobe and the one on the right is from the left upper lobe. The constitutional gene, cytochrome oxidase, subunit II, is shown at the bottom. 


\section{Results}

Fetal weight, lung weight, lung phospholipid, and DNA content. There were no differences in the weights of the fetuses between the treatment groups of fetal rabbits (gestational age 25 d) treated intraamniotically with IL- $1 \alpha$ or vehicle on d 23.3 of gestation. Lung weight, protein, and DNA content were likewise similar in the different groups (Table I).

The total phospholipid content was higher in the lungs of fetuses treated with a high dose of IL- $1 \alpha$ (1,500 ng/fetus) than in those of the controls (Table I). There was also a tendency for the IL- $1 \alpha$-treated animals to have a higher DPC content in their lungs $(P=0.05)$. In the group treated with the lower IL$1 \alpha$ dose (150 ng/fetus), the phospholipid content also tended to be higher, but this difference was not significant. The group treated with IL-1ra did not differ from the corresponding control group with respect to lung phospholipid or DPC content (Table I).

$S P-A,-B$, and $-C m R N A$ in fetal rabbit lungs on day 25. Fig. 1 shows the mRNA expression of SP-A, -B, and -C in the lungs of IL- $1 \alpha$-treated and control fetuses. IL- $1 \alpha$ increased the expression of SP-A and -B mRNA, but did not change the expression of SP-C mRNA. Fig. 2 summarizes the effect of IL- $1 \alpha$ on surfactant protein expression. For each cytokine dose, the results of six litters of fetuses are shown. IL-1 $\alpha$ stimulated in a dose-dependent fashion the expression of SP-A and -B mRNA. There was no difference in surfactant protein expression between the upper and lower lobes and between female and male fetuses (data not shown).

Fig. 3 shows the surfactant protein expression in fetuses treated with IL-1ra. The data is obtained from five litters of fetuses. There were no differences in the expression of any of the three surfactant proteins between the IL-1ra-treated and the control fetuses.

Immunohistochemistry for $S P-B$, and surfactant components in $B A L$. Immunostaining for SP-B was more intense in IL- $1 \alpha$-treated than in control lungs (Fig. 4). In both groups,

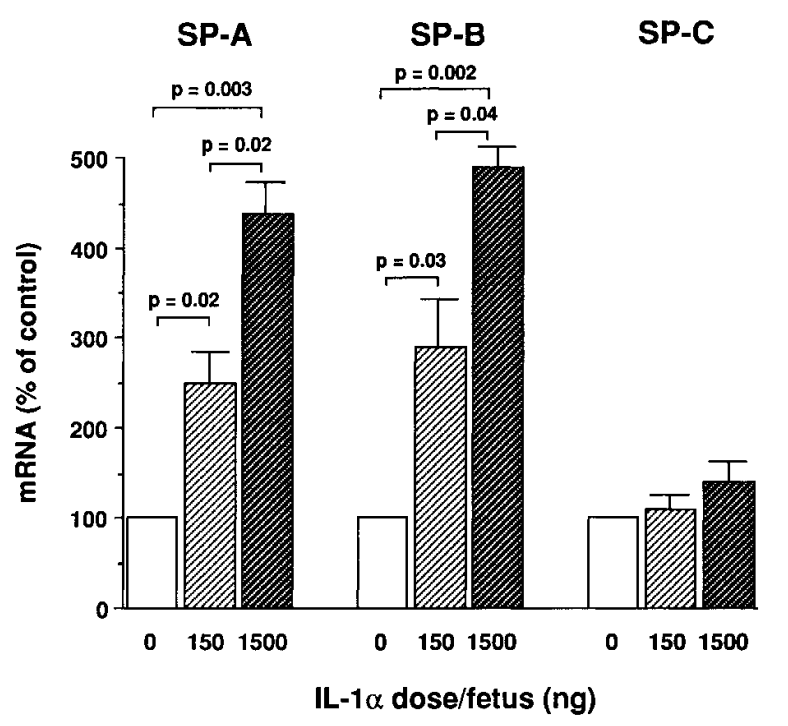

Figure 2. SP-A, -B, and -C mRNA expression in lungs of 25-d-old fetuses treated with intraamniotic IL- $1 \alpha$. Results of six litters are shown for each cytokine dose.

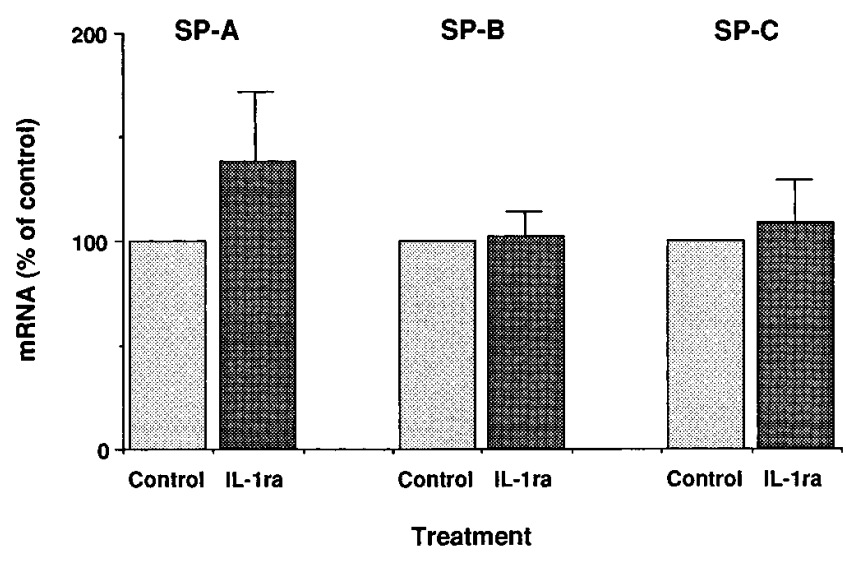

Figure 3. SP-A, -B, and -C mRNA expression in lungs of 25-d-old fetuses treated with intraamniotic IL-1ra ( $20 \mu \mathrm{g} /$ fetus $)$. Results from five litters of fetuses are shown.

several fields from four lungs were evaluated. The percentage of alveolar epithelial cells stained for SP-B from IL- $1 \alpha$-treated animals was $56 \pm 13 \%$; this was not significantly higher than vehicle-treated animals $(42 \pm 9 \%)$. IL-1 treatment did not increase the number of inflammatory cells in the lung.

IL- $1 \alpha$-treated fetuses had a higher concentration of SP-B in BAL return than the placebo-treated ones. DPC concentrations in BAL return were also increased in fetuses treated with IL-1 $\alpha$ (Table II). Similar to SP-B, the SP-A staining of the SDS gels was more prominent after IL- $1 \alpha$ than after vehicle, with the glycosylated SP-A $(36 \mathrm{kD})$ being the main component in each case (data not shown).

Lung compliance and the expansion patterns of the lungs. Fetuses were treated with IL- $1 \alpha(1,500 \mathrm{ng} /$ fetus $)$ or the corresponding vehicle on day 25 of gestation. On day 27 of gestation, the fetuses were ventilated in total body plethysmographs as described in Methods. The dynamic lung compliance measured after 2 min of ventilation of IL- $1 \alpha$-treated fetuses was significantly greater than that of control fetuses (Fig. 5).

Compared with placebo-treated animals, the IL- $1 \alpha$-treated pups had greater quasistatic lung volumes at inflation pressures higher than $25 \mathrm{~cm} \mathrm{H}_{2} \mathrm{O}$, and at all deflation pressures studied. At 35 and $0 \mathrm{~cm} \mathrm{H}_{2} \mathrm{O}$, the lung volumes of the IL- $1 \alpha-$ treated animals were $56.9 \pm 11.2$ and $10.4 \pm 3.7 \mathrm{ml} / \mathrm{kg}$, respectively; the corresponding figures for the placebo-treated animals were $14.6 \pm 2.7(P<0.02)$ and $0.7 \pm 0.8 \mathrm{ml} / \mathrm{kg}(P<0.02)$. As seen in Fig. 6, lungs treated with IL-1 $\alpha$ showed a better and more homogeneous aeration and less necrosis of airway epithelium after ventilation than the control lungs. The alveolar volume density in IL- $1 \alpha$-treated lungs, compared with lungs from placebo-treated animals was increased $(0.51 \pm 0.08$ vs. $0.12 \pm 0.02 ; n=6 ; P=0.01)$. There was no evidence of an increase in inflammatory cells in the lung fields of animals treated with IL- $1 \alpha$ and mechanical ventilation.

Effect of IL-1 $\alpha$ on expression of SP-A $m R N A$ in fetal rabbit lung explants in culture. IL- $1 \alpha$ at $570 \mathrm{ng} / \mathrm{ml}$ enhanced the expression of SP-A mRNA in fetal rabbit lung explants by $184 \pm 39 \%(P=0.02)$, whereas dibutyryl cAMP at $1 \mathrm{mM}$ increased SP-A mRNA expression by $236 \pm 40 \%(P=0.01$; NS compared with IL-1 $\alpha$ ). The effect of IL-1 $\alpha$ was dose dependent. Dibutyryl cAMP increased the expression of SP-B 

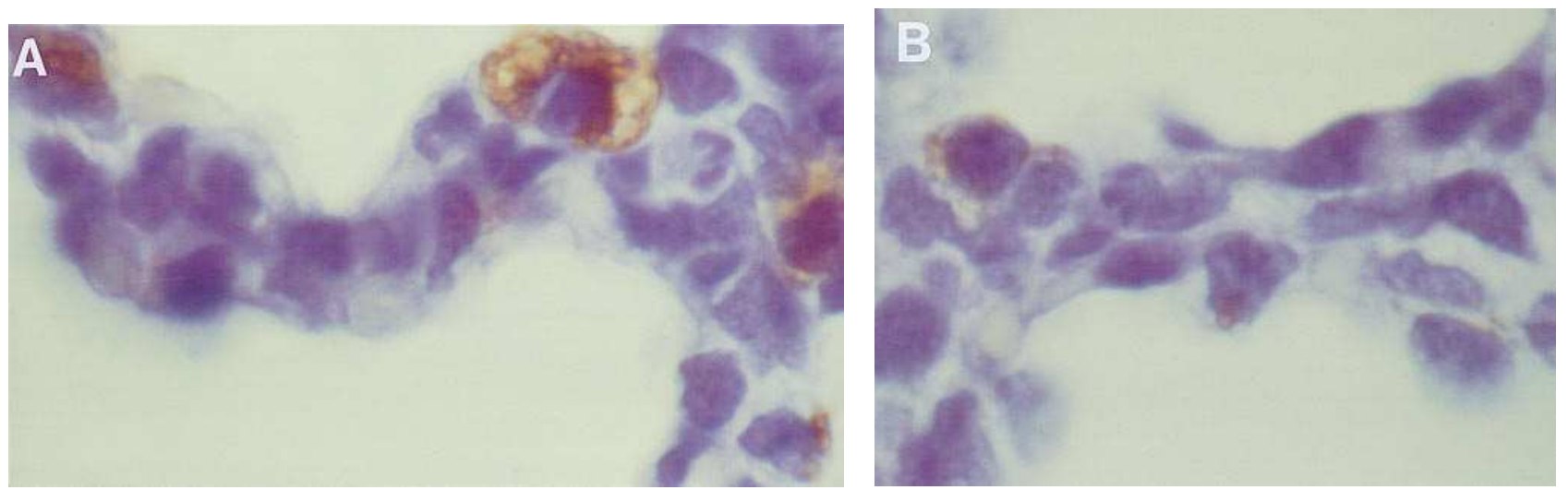

Figure 4. Immunostaining for SP-B of pulmonary alveolar cells from 27 -d-old IL- $1 \alpha$-treated (1,500 ng/fetus) $(A)$ and placebo-treated $(B)$ fetuses.

mRNA, whereas IL-1 $\alpha$ had no effect on SP-B mRNA in vitro (data not shown).

\section{Discussion}

The present study shows for the first time that intraamniotic administration of a cytokine modulates lung maturation, without affecting fetal lung growth. IL- $1 \alpha$ accelerated the expression of SP-A and -B, but did not affect SP-C mRNA. IL- $1 \alpha$ also stimulated the expression of SP-A in fetal rabbit lung explants in culture, whereas under these conditions SP-B was unaffected. On the other hand, IL-1ra, which is present in high concentration in amniotic fluid (18), did not modify the expression of SP-A, -B, or -C mRNA when given in excess intraamniotically to fetal rabbits or added to fetal lung cultures (34). This suggests that endogenous IL-1 activity does not play a role in the expression of surfactant proteins in fetal lung during normal preterm gestation.

Various proinflammatory cytokines accumulate in amniotic fluid in labor associated with intrauterine infection (19, $35)$. In this condition, the concentration of IL-1 (IL-1 $\alpha+$ IL-1 $\beta$ ) is within the range required for acceleration of surfactant protein synthesis in fetal lung explants, and attainable with intraamniotic injections of $150-1,500 \mathrm{ng}$ of IL- $1 \alpha$ to fetal rabbits (19). Proinflammatory cytokines participate in the onset and progression of labor. In the present study, no cases of preterm birth occurred during the 40-h period after IL-1 $\alpha$ treatment. An increased incidence of preterm birth, induced by proin- flammatory cytokines (combination of IL- $1 \alpha$ and TNF- $\alpha$ ) occurs first $3 \mathrm{~d}$ after intraamniotic cytokine injections in rabbits (36).

Surfactant synthesis is regulated by several hormones, most notably glucocorticoid (37). Depending on the concentration, corticosteroids stimulate or inhibit the expression of SP-A in human fetal lung explants (38). Administration of dexamethasone to pregnant rats upregulates the expression of SP-A and to a lesser degree that of SP-B and -C (39). Administration of glucocorticoid to the doe or the fetus decreases fetal lung growth (37).

In addition to hormones, some cytokines have been proposed to have a role in the differentiation of alveolar type II cells. EGF, TGF- $\alpha$, IL-1, and IFN- $\gamma$ stimulate the production of various surfactant components. EGF enhances the rate of choline incorporation into disaturated phosphatidylcholine in explants of fetal rat lung (40) and stimulates phosphatidylcholine synthesis in alveolar type II cells isolated from fetal rabbit lung (41). In explants of human fetal lung obtained between 15 and 24 wk of gestation, EGF stimulates the synthesis of SP-A and the expression of SP-A mRNA (42). Intraamniotic and simultaneous intraperitoneal injection of EGF increases SP-A concentration as well as the lecithin/sphingomyelin ratio in the amniotic fluid of fetal rhesus monkeys (43). IFN- $\gamma$ increases SP-A expression in human fetal lung explants (44) and in adenocarcinoma cells (45). On the other hand, cytokines such as TNF- $\alpha$ and $-\beta$ downregulate the synthesis and expression of surfactant proteins and lipids. TNF- $\alpha$ decreases expression of

Table II. The Concentrations of the Phospholipids and Surfactant Protein B in BAL from 27-d-old Fetuses Treated Intraamniotically with IL-1 $\alpha$ or Placebo on Day 25.3 of Gestation

\begin{tabular}{|c|c|c|c|c|}
\hline & \multicolumn{2}{|c|}{ IL-1 $\alpha$ (1500 ng/fetus) } & \multicolumn{2}{|c|}{ IL-1 $\alpha$ (150 ng/fetus) } \\
\hline & Drug & Placebo & Drug & Placebo \\
\hline$n$ & 9 & 8 & 8 & 6 \\
\hline Total phospholipids $(\mu \mathrm{M})$ & $62.3 \pm 4.3$ & $48.0 \pm 5.2$ & $82.6 \pm 6.8$ & $43.9 \pm 3.7$ \\
\hline Phosphatidylcholine $(\mu \mathrm{M})$ & $49.3 \pm 6.8$ & $36.4 \pm 5.4$ & $71.9 \pm 18.2 *$ & $32.1 \pm 7.7$ \\
\hline Disaturated phosphatidylcholine $(\mu \mathrm{M})$ & $24.3 \pm 3.8$ & $14.1 \pm 1.8$ & $40.5 \pm 13.3^{*}$ & $16.3 \pm 3.6$ \\
\hline Surfactant protein B (ng/ml) & $188 \pm 25 *$ & $90 \pm 17$ & $209 \pm 17 *$ & $78 \pm 141$ \\
\hline
\end{tabular}

Values are mean \pm SEM. ${ }^{*} P<0.05$ compared with placebo treatment. 


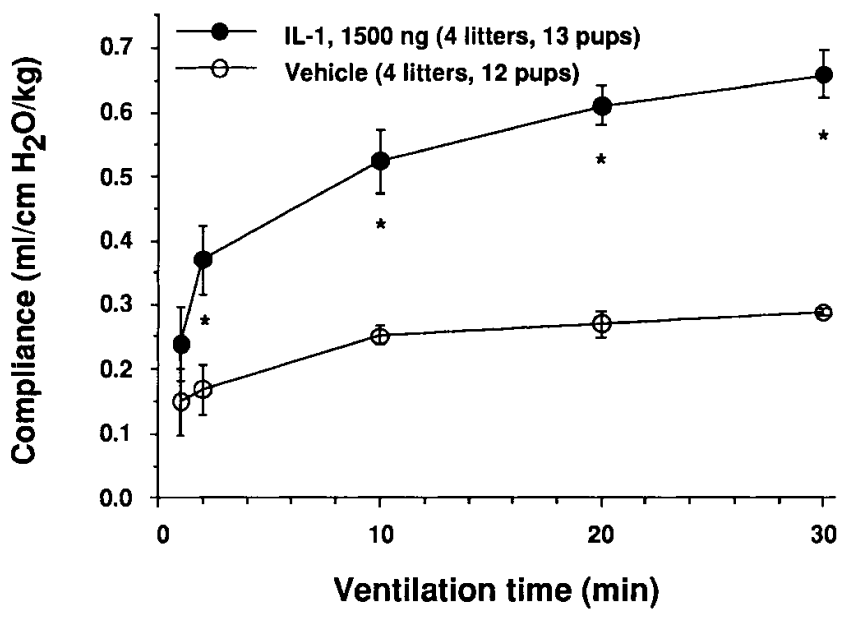

Figure 5. Dynamic lung compliance of IL- $1 \alpha$-treated (1,500 ng/fetus) and vehicle-treated 27 -d-old fetal rabbits (4 litters, 25 animals) ventilated in total body plethysmographs. After 2 min of ventilation, IL- $1 \alpha$-treated animals had higher compliance than the controls $(P<0.05)$.

SP-A and -B in human pulmonary adenocarcinoma cells (45) and in human lung explants (46). TNF- $\alpha$ also inhibits phosphatidylcholine synthesis in human type II alveolar cells isolated from adult human lung tissue (47). Likewise, TGF- $\beta$ inhibits the expression of SP-A mRNA and production of SP-A protein in explants of human fetal lung (42) as well as in pulmonary adenocarcinoma cells in culture (48).

Intraamniotic IL-1 may act on the expression of surfactant proteins by several mechanisms. The cytokine may reach the alveoli either directly by fetal breathing movements or by being absorbed into the fetal circulation from the gastrointestinal tract or from fetal membranes. It is possible that IL-1 has a direct stimulatory effect on the synthesis and secretion of surfactant components by type II cells. IL-1 may also act on other fetal cells, such as the alveolar macrophage or the type II alveolar cell to stimulate the production of another agent such as PGE (6), known to stimulate SP-A expression (49). In addition, IL-1 in amniotic fluid may induce in amnion cells the production of mediators such as $\mathrm{PGE}_{2}$, which in turn may promote surfactant protein expression in type II cells.

It can be envisaged that IL-1 increases the production of ACTH-releasing hormone and glucocorticoids by the fetus (50). Activation of the hypothalamic-pituitary-adrenal axis by IL-1 has been shown to occur in newborn animals (51). Stimulation of corticosteroid production would therefore possibly contribute to enhanced expression of surfactant components (37-39). In young animals, corticosterone production in response to IL-1 shows sexual dimorphism, with female animals releasing more corticosterone in response to the cytokine than do males (52). This is of interest in view of the more advanced maturation of the surfactant system occurring in mammalian females and of an apparently higher responsiveness of the immature female lung to factors stimulating the synthesis of DPC (53). On the other hand, human female fetuses have higher IL1ra concentrations in the amniotic fluid than do males (18). It remains to be studied whether maternal chorioamnionitis affects the gender difference in lung maturation. In the present study, injection of IL-1 into the amniotic fluid did not lead to elevated cortisol levels in fetal plasma (IL-1 $\alpha: 4.14 \pm 0.22 \mathrm{ng} / \mathrm{ml}$ vs. vehicle $3.61 \pm 1.17, n=5$ ). There was no gender difference in the expression of surfactant proteins among the IL-1- or placebo-treated fetuses.

Activation of the glucocorticoid axis is not likely to be the sole mechanism of IL-1-induced functional maturation of the lung, since IL-1 increased SP-A expression also in lung explants in vitro. IL-1 is known to affect either the stability (54) or the transcription rate (55) of specific genes. Activator protein-1 is one of the nuclear transcription factors that, as a result of IL-1-induced activation, binds to specific consensus sequences, enhancing the gene transcription rate (55). A highly conserved activator protein-1 consensus was recently identified upstream from the transcription initiation site of the SP-D gene (56). However, a similar sequence has thus far not been associated with the SP-A or -B gene. In spite of the clear cut
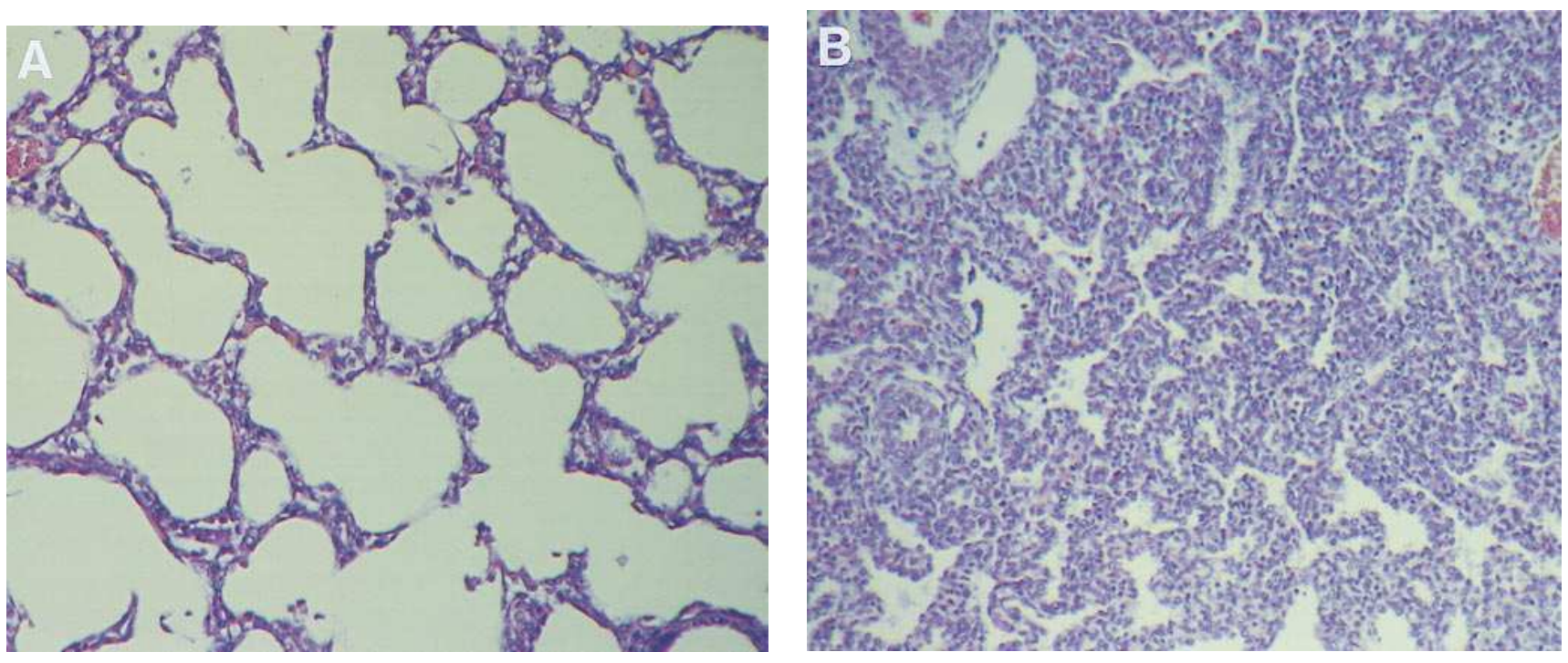

Figure 6. Expansion patterns of ventilated lungs from 27 -d-old fetal rabbits: from an IL- $1 \alpha$-treated (1,500 ng) fetus $(A)$ and from a vehicletreated littermate $(B)$. 
stimulation of SP-B mRNA and SP-B content in immature lung in vivo, the failure of IL-1 to affect SP-B mRNA in vitro supports the possibility that this gene was upregulated by an extrapulmonary secondary mediator.

IL-1 concentrations are elevated in amniotic fluid in patients in premature labor with intraamniotic infection (19). Here we show that intraamniotic IL-1 increased SP-B and disaturated phosphatidylcholine in the lung. These surfactant components are required for alveolar stability $(1,2)$. In addition, IL-1 increased SP-A that, besides promoting the surface activity $(24,27)$, together with SP-D enhances the microbicidal activity of alveolar macrophages in vitro (4). Consistent with these findings, we demonstrated a striking improvement in dynamic compliance and homogeneous alveolar expansion of ventilated preterm animals after intraamniotic IL- $1 \alpha$. In contrast, intramuscular injection of IL-1 $\alpha(1.5-1,500 \mathrm{ng})$ to rabbit fetus had no detectable effect on the expression of surfactant proteins (K. Bry et al., unpublished observations). By promoting lung maturation, accumulation of IL-1 in the amniotic fluid may be a part of a host-defense mechanism that prepares the fetus for preterm birth and extrauterine life.

\section{Acknowledgments}

We thank Hazel Hernandez and Mila Ibardolaza for excellent technical assistance.

This research was supported by the Foundation for Maternal and Infant Care (Orange County, CA).

\section{References}

1. Hawgood, S., B.J. Benson, J. Schilling, D. Damm, J.A. Clements, and R.T. White. 1987. Nucleotide and amino acid sequences of pulmonary surfactant protein SP 18 and evidence for cooperation between SP 18 and SP 28-36 in surfactant lipid adsorption. Proc. Natl. Acad. Sci. USA. 84:66-70.

2. Revak, S., T.A. Merritt, E. Degryse, L. Stefani, M. Courtney, M. Hallman, and G.C. Cochrane. 1988. Use of human surfactant low molecular weight (LMW) apoproteins in the reconstitution of surfactant biological activity. $J$. Clin. Invest. 81:826-833.

3. King, R.J., and M.C. MacBeth. 1979. Physicochemical properties of dipalmitoyl phosphatidylcholine after interaction with an apolipoprotein of pulmonary surfactant. Biochim. Biophys. Acta. 557:86-101.

4. Haagsman, H.P. 1994. Surfactant proteins A and D. Biochem. Soc. Trans. 22:100-106.

5. Dinarello, C.A. 1991. Interleukin-1 and interleukin-1 antagonism. Blood. 77:1627-1652

6. Dinarello, C.A. 1992. Role of interleukin-1 in infectious diseases. Immunol. Rev. 127:119-146.

7. Van der Meer, J.W.M., M. Barza, S.M. Wolff, and C.A. Dinarello. 1988. A low dose of recombinant interleukin 1 protects granulocytopenic mice from lethal gram-negative infection. Proc. Natl. Acad. Sci. USA. 85:1620-1623.

8. Wallach, D., H. Holtmann, H.M. Engelmann, and Y. Nophar. 1988. Sensitization and desensitization to lethal effects of tumor necrosis factor and IL-1. J. Immunol. 140:2994-2999.

9. Denis, M., and E. Ghadirian. 1994. Interleukin-1 is involved in mouse resistance to Mycobacterium avium. Infect. Immun. 62:457-461.

10. Kauma, S., D. Matt, S. Strom, D. Eierman, and T. Turner. 1990. Interleukin-1 $\beta$, human leukocyte antigen HLA-DR $\alpha$, and transforming growth factor- $\beta$ expression in endometrium, placenta, and placental membranes. Am. J. Obstet. Gynecol. 163:1430-1437.

11. Menon, R., K.F. Swan, T.W. Lyden, N.S. Rote, and S.J. Fortunato. 1995. Expression of inflammatory cytokines (interleukin-1 $\beta$ and interleukin-6) in amniochorionic membranes. Am. J. Obstet. Gynecol. 172:493-500.

12. Arend, W.P. 1991. Interleukin-1 receptor antagonist. A new member of the interleukin 1 family. J. Clin. Invest. 88:1445-1451.

13. Fisher, C.J., Jr., J.F. Dhainaut, S.M. Opal, J.P. Pribble, R.A. Balk, G.J. Slotman, T.J. Iberti, E.C. Rackow, M.J. Shapiro, R.L. Greenman, et al. 1994. Recombinant human interleukin-1 receptor antagonist in the treatment of patients with sepsis syndrome. Results from a randomized, double-blind, placebocontrolled trial. Phase III rhIL-1ra Sepsis Syndrome Study Group. JAMA (J. Am. Med. Assoc.). 271:1836-1843.

14. Havell, E.A., L.L. Moldawer, D. Helfgott, P.L. Kilian, and P.B. Sehgal.
1992. Type I IL-1 receptor blockade exacerbates murine listeriosis. J. Immunol. 148:1486-1492.

15. Mancilla, J., J.P. Garcia, and C.A. Dinarello. 1993. IL-1 receptor antagonist can either protect or enhance the lethality of Klebsiella pneumoniae sepsis in newborn rats. Infect. Immun. 61:926-932.

16. Galve-de-Rochemonteix, B., L.P. Nicod, R. Chicheportiche, S. Lacraz, C. Baumberger, and J.M. Dayer. 1993. Regulation of interleukin-1ra, interleukin- $1 \alpha$, and interleukin- $1 \beta$ production by human alveolar macrophages with phorbol myristate acetate, lipopolysaccharide, and interleukin-4. Am. J. Respir. Cell Mol. Biol. 8:160-168.

17. Bry, K., U. Lappalainen, M. Hallman, and S.P. Eisenberg. 1995. Hydrocortisone stimulates interleukin-1 receptor antagonist production and mRNA expression in amnion cells. Pediatr. Res. 37:59a. (Abstr.)

18. Bry, K., U. Lappalainen, F. Waffarn, K. Teramo, and M. Hallman. 1994 Influence of fetal gender on the concentration of interleukin-1 receptor antagonist in amniotic fluid and in newborn urine. Pediatr. Res. 35:130-134.

19. Romero, R., M. Mazor, F. Brandt, W. Sepulveda, C. Avila, D.B. Cotton, and C.A. Dinarello. 1992. Interleukin- $\alpha$ and interleukin-1 $\beta$ in preterm and term human parturition. Am. J. Reprod. Immunol. 27:117-123.

20. Watterberg, K.L., L.M. Demers, S.M. Scott, and S. Murphy. 1996. Chorioamnionitis and early lung inflammation in infants in whom bronchopulmonary dysplasia develops. Pediatrics. 97:210-215.

21. Nizet, V., R.L. Gibson, E.Y. Chi, P.E. Framson, M. Hulse, and C.E. Rubens. 1996. Group B streptococcal beta-hemolysin expression is associated with injury of lung epithelial cells. Infect. Immun. 64:3818-3826.

22. Smith, P.K., R.I. Krohn, G.T. Hermanson, A.K. Malia, F.H. Gartner, M.D. Provenzano, E.K. Fujimoto, N.M. Goeke, B.J. Olson, and D.C. Klenk 1985. Measurement of protein using bicinchoninic acid. Anal. Biochem. 150:7685 .

23. Shapiro, O.L., and B.K. Schrier. 1973. Cell cultures of fetal rat brain. Growth and marker enzyme development. Exp. Cell Res. 77:239-247.

24. Rider, E.D., M. Ikegami, J.A. Whittsett, W. Hull, M. Absolom, and A.H. Jobe. 1993. Treatment responses to surfactants containing natural surfactant proteins in preterm rabbits. Am. Rev. Respir. Dis. 147:669-676.

25. Robertson, B., and B. Lachmann. 1988. Experimental evaluation of surfactants for replacement therapy. Exp. Lung Res. 14:279-310.

26. Chomczynski, P., and N. Sacchi. 1987. Single-step method of RNA isolation by acid guanidium thiocyanate-phenol-chloroform extraction. Anal. Biochem. 162:156-159.

27. Hallman, M., T.A. Merritt, T. Akino, and K. Bry. 1991. Surfactant protein A, phosphatidylcholine and surfactant inhibitors in epithelial lining fluid. Correlation with surface activity, severity of RDS and outcome of small premature infants. Am. Rev. Respir. Dis. 144:1376-1384.

28. Laemmli, U.K. 1970. Cleavage of structural proteins during the assembly of the head of the bacteriophage T4. Nature (Lond.). 227:680-685.

29. Krämer, H.J., R. Schmidt, A. Günther, G. Becker, Y. Suzuki, and W. Seeger. 1995. ELISA technique for quantification of surfactant protein B (SP-B) in bronchoalveolar lavage fluid. Am. J. Respir. Crit. Care Med. 152:1540-1544.

30. Beers, M.F., S.R. Bates, and A.B. Fisher. 1992. Differential extraction for the rapid purification of bovine surfactant protein B. Am. J. Physiol. 262: L773-L778.

31. Bligh, E.G., and W.J. Dyer. 1957. A rapid method of total lipid extraction and purification. Can. J. Biochem. Physiol. 37:911-917.

32. Mason, R.J., J. Nellenbogen, and J.A. Clements. 1976. Isolation of disaturated phosphatidylcholine with osmium tetroxide. J. Lipid Res. 17:281-284

33. Snyder, J.M., C.R. Mendelson, and J.M. Johnston. 1981. The effect of cortisol on rabbit fetal lung maturation in vitro. Dev. Biol. 85:129-140.

34. Dhar, V., M. Hallman, U. Lappalainen, and K. Bry. 1997. Interleukin $1 \alpha$ upregulates the expression of surfactant protein-A in rabbit lung explants. Biol. Neonate. 71:46-52.

35. Romero, R., M. Mazor, W. Sepulveda, C. Avila, D. Copeland, and J. Williams. 1992. Tumor necrosis factor in term and preterm labor. Am. J. Obstet. Gynecol. 166:1576-1587.

36. Bry, K., and M. Hallman. 1993. Transforming growth factor- $\beta$ prevents preterm delivery induced by interleukin- $1 \alpha$ and tumor necrosis factor- $\alpha$ in the rabbit. Am. J. Obstet. Gynecol. 168:1318-1322.

37. Post, M., and B.T. Smith. 1992. Hormonal control of surfactant metabolism. In Pulmonary Surfactant: from Molecular Biology to Clinical Practice. B. Robertson, L.M.G. Van Golde, and J.J. Batenburg, editors. Elsevier Science, Amsterdam, The Netherlands. 379-424.

38. Odom, M.J., J.M. Snyder, Y. Boggaram, and C.R. Mendelson. 1988 Glucocorticoid regulation of the major surfactant-associated protein (SP-A) and its mRNA and of morphologic development of human fetal lung in vitro. Endocrinology. 123:1712-1720.

39. Schellhase, D.E., and J.M. Shannon. 1991. Effects of maternal dexamethasone expression of SP-A, SP-B and SP-C in the fetal rat lung. Am. J. Respir. Cell Mol. Biol. 4:304-312.

40. Gross, I., D.W. Dynia, S.A. Rooney, D.A. Smart, J.B. Warshaw, J.F. Sissom, and S.B. Hoath. 1986. Influence of epidermal growth factor on fetal lung development in vitro. Pediatr. Res. 20:473-477.

41. Haigh, R.M., M. Hollingsworth, L.A. Micklewright, R.D.H. Boyd, and S.W. D'Souza. 1988. The effect of human urogastrone on lung phospholipids in 
fetal rabbits. J. Dev. Physiol. 10:433-443.

42. Whitsett, J.A., T.E. Weaver, M.A. Lieberman, J.C. Clark, and C. Daugherty. 1987. Differential effects of epidermal growth factor and transforming growth factor- $\beta$ on synthesis of $\mathrm{M}_{\mathrm{r}}=35,000$ surfactant-associated protein in fetal lung. J. Biol. Chem. 262:7908-7913.

43. Goetzman, B.W., L.C. Read, C.G. Plopper, A.F. Tarantal, C. GeorgeNascimento, T.A. Merritt, J.A. Whitsett, and D. Styne. 1994. Prenatal exposure to epidermal growth factor attenuates respiratory distress syndrome in rhesus infants. Pediatr. Res. 35:30-36.

44. Ballard, P.L., H.G. Liley, L.W. Gonzales, M.W. Odom, A.J. Ammann, B. Benson, R.T. White, and M.C. Williams. 1990. Interferon- $\gamma$ and synthesis of surfactant components by cultured human lung. Am. J. Respir. Cell Mol. Biol. 2: $137-143$.

45. Wispe, J.R., J.C. Clark, B.B. Warner, D. Fajardo, W.E. Hull, R.B. Holtzman, and J.A. Whitsett. 1990. Tumor necrosis factor-alpha inhibits expression of pulmonary surfactant protein. J. Clin. Invest. 86:1954-1960.

46. Dulkerian, S.J., and P.L. Ballard. 1994. Effects of inflammatory mediators on surfactant proteins A and B. Pediatr. Res. 35:296a. (Abstr.)

47. Arias-Diaz, J., E. Vara, C. Garcia, and J.L. Balibrea. 1994. Tumor necrosis factor- $\alpha$-induced inhibition of phosphatidylcholine synthesis by human type II pneumocytes is partially mediated by prostaglandins. J. Clin. Invest. 94: $244-250$

48. Whitsett, J.A., A. Budden, W.M. Hull, J.C. Clark, and M.A. O'Reilly. 1992. Transforming growth factor- $\beta$ inhibits surfactant protein A expression in vitro. Biochim. Biophys. Acta. 1123:257-262.

49. Acarregui, M.J., J.M. Snyder, M.D. Mitchell, and C.R. Mendelson. 1990. Prostaglandins regulate surfactant protein A (SP-A) gene expression in human fetal lung in vitro. Endocrinology. 127:1105-1113

50. Gwosdow, A.R., M.S. Kumar, and H.H. Bode. 1990. Interleukin-1 stimulation of the hypothalamic-pituitary-adrenal axis. Am. J. Physiol. 258:E65E70.

51. Barna, I., Z. Acs, G. Bugovics, and J.I. Koenig. 1995. Effect of interleukin-1 $\beta$ on plasma ACTH, beta-endorphin, and corticosterone in infant and prepubertal rats. Pediatr. Res. 37:714-719.

52. Rivier, C. 1994. Stimulatory effect of interleukin-1 $\beta$ on the hypothalamic-pituitary-adrenal axis of the rat: influence of age, gender and circulating sex steroids. J. Endocrinol. 140:365-372.

53. Klein, J.M., and H.C. Nielsen. 1993. Androgen regulation of epidermal growth factor receptor binding activity during fetal rabbit lung development. $J$. Clin. Invest. 91:425-431.

54. Stoechle, M.Y. 1991. Post-translational regulation of gro $\alpha, \beta$, $\gamma$, and IL-8 mRNAs by IL-1ß. Nucleic Acids Res. 19:917-920.

55. Saklatvala, J. 1995. Intracellular signaling mechanisms of IL-1 and TNF: possible targets for therapy. Br. Med. Bull. 51:402-418.

56. Rust, K., L. Bingle, W. Mariencheck, A. Persson, and E.C. Croch. 1996. Characterization of the human surfactant protein D promoter: transcriptional regulation of SP-D gene expression by glucocorticoids. Am. J. Resp. Cell Mol. Biol. 14:121-130. 